InTroduction: Complement activation occurs secondary to a variety of external stimuli. Lactic acidosis has been previously shown to activate the complement factors $\mathrm{C} 3 \mathrm{a}$ and $\mathrm{C5a}$. In the present investigation we examined the differential effect of lactic acidosis on anaphylatoxin levels in cord and adult blood. Furthermore we aimed to determine if the entire complement cascade could be activated by lactic acidosis.

Metbods: Cord and adult blood samples $(n=20$ each) were collected and incubated for one hour in either untreated condition or with the addition of lactate in two concentrations $(5.5 \mathrm{mmol} / 1$ vs $22 \mathrm{mmol} / 1)$. Following incubation, levels of $\mathrm{C} 3 \mathrm{a}, \mathrm{C} 5 \mathrm{a}$ and $\mathrm{sC} 5 \mathrm{~b}-9$, and blood gas parameters were determined.

Results: Anaphylatoxin (C3a and C5a) and sC5b-9 levels increased with the addition of lactate in a dosedependent manner in cord and adult blood (C3a: $1 \mathrm{~h}$, $5.5 \mathrm{mmol} / 1, \quad 22 \mathrm{mmol} / \mathrm{l}$ : $418 / 498 / 622 \mu \mathrm{g} / 1$ in cord blood; 1010/1056/1381 $\mu \mathrm{g} / 1$ in adult blood, $p<0,05$; similar results were found for $\mathrm{C} 5 \mathrm{a}$ and $\mathrm{sC} 5 \mathrm{~b}-9)$.

Conclusion: Lactic acidosis leads to an activation of the entire complement system in neonates and in adults. This activation is dose-dependent and more pronounced in adults as compared to neonates.

Key words: Lactate, Cord blood, Adult blood, Complement, Activation, Anaphylatoxins

\section{In-vitro activation of complement system by lactic acidosis in newborn and adults}

\author{
Friederike Hecke, Thomas Hoehn ${ }^{\text {CA }}$, Evelyn Strauss, \\ Michael Obladen and Josef Sonntag
}

Department of Neonatology, Charité Virchow Hospital, Humboldt University, 13353 Berlin, Germany

${ }^{\mathrm{CA}}$ Corresponding Author
Tel: +493045066413
Fax: +493045066922
E-mail: thomas.hoehn@charite.de

\section{Introduction}

Activation of the complement system occurs due to a variety of conditions. These are either associated with hypoxia or with cellular damage resulting in acidosis during conditions like birth asphyxia or infection. ${ }^{1-4}$ The components of damaged tissue like mitochondrial fractions or other subcellular components cause activation of complement via the alternative pathway. ${ }^{5,6}$ As we have shown previously, lactic acidosis itself can result in activation of $\mathrm{C} 5 \mathrm{a}$ even in the absence of cellular components. ${ }^{7}$ The aim of this study was to investigate whether lactic acidosis led to an activation of the entire complement cascade and to look for differences in complement activation between neonatal and adult blood. Furthermore we aimed to determine whether anticoagulation with heparin or citrate led to different levels of activation of the complement system.

\section{Materials and methods}

Following informed consent, blood samples of $10 \mathrm{ml}$ were collected in polypropylene tubes from the placenta of 20 term newborns without acidosis (base excess $<-10)$ and 20 healthy adult volunteers. Each specimen was devided into two samples of $5 \mathrm{ml}$ and either 100 units of heparin or $0.5 \mathrm{ml}$ sodium-citrate was added for anticoagulation. Four $5 \mathrm{ml}$ samples (heparin-placenta-blood, citrate-placenta-blood, heparin-adult-blood, citrate-adult-blood) were devided in 3 portions and remained untreated, were treated with lactate $0.5 \mathrm{mg}(5.5 \mu \mathrm{mol} / \mathrm{l})$ or with lactate $2 \mathrm{mg}$ $(22 \mu \mathrm{mol} / \mathrm{ml})$. Samples were incubated for $60 \mathrm{~min}$ at $37^{\circ} \mathrm{C}$. Following incubation $1 \mathrm{mg}$ disodium-ethylendiaminetetra-acetic-acid was added to the heparin samples to stop complement activation and samples were centrifuged immediately. The remainder was stored at $-80^{\circ} \mathrm{C}$. Blood $\mathrm{pH}$, potassium, lactate concentration, $\mathrm{pCO}_{2}$, and base excess were measured in all samples prior to and following incubation. C5a and C3a were quantified by the use of a specific sandwich enzyme immuno assay (Behring, Marburg, Germany). The terminal complement complex was measured by the Elisa technique detecting the soluble sC5b-9 (LD Labordiagnostik, Heiden, Germany).

\section{Statistical analysis}

As most data were not normally distributed, results were expressed as medians with quartiles. Differences between placental and adult samples were assessed by the Wilcoxon test. Statistical significance was assumed at $p<0.05$. All calculations and tests were performed with the SPSS-PC-Software 9.0 (Chicago, IL, USA). 
Table 1. Base deficit and lactate concentration for cord and adult blood at $0 \mathrm{~h}, 1 \mathrm{~h}$, and after equilibration with lactate $(5.5 \mathrm{mmol} / \mathrm{l}$ and $22 \mathrm{mmol} / \mathrm{l}$ )

\begin{tabular}{|c|c|c|c|c|c|c|c|}
\hline & \multicolumn{3}{|c|}{ Cord blood } & \multicolumn{3}{|c|}{ Adult blood } & \multirow[t]{2}{*}{ Significance } \\
\hline & median & P25 & P75 & median & P25 & P75 & \\
\hline \multicolumn{8}{|l|}{ Base deficit } \\
\hline $\mathrm{Oh}$ & 8.35 & 7.03 & 9.35 & 3.70 & 2.30 & 4.65 & $p<0.05$ \\
\hline $1 \mathrm{~h}$ & 10.10 & 9.00 & 11.10 & 4.75 & 3.85 & 6.20 & $p<0.05$ \\
\hline $5.5 \mathrm{mmol} / \mathrm{l}$ & 15.80 & 13.83 & 17.05 & 10.85 & 8.43 & 11.88 & $p<0.05$ \\
\hline $22 \mathrm{mmol} / \mathrm{l}$ & 29.25 & 26.60 & 31.42 & 25.25 & 22.82 & 27.35 & $p<0.05$ \\
\hline \multicolumn{8}{|c|}{ Lactate $[\mathrm{mmol} / \mathrm{l}]$} \\
\hline $\mathrm{Oh}$ & 3.30 & 2.40 & 3.88 & 1.02 & 0.82 & 1.18 & $p<0.05$ \\
\hline $1 \mathrm{~h}$ & 5.12 & 4.36 & 5.51 & 2.70 & 2.34 & 3.23 & $p<0.05$ \\
\hline $5.5 \mathrm{mmol} / \mathrm{l}$ & 10.53 & 8.66 & 11.68 & 7.80 & 7.26 & 8.95 & $p<0.05$ \\
\hline $22 \mathrm{mmol} / \mathrm{l}$ & 21.22 & 14.45 & 23.97 & 18.21 & 13.75 & 24.56 & n.s. \\
\hline
\end{tabular}

\section{Results}

Baseline levels of $\mathrm{pH}$ were not different between umbilical cord (7.34 [7.30/7.38]) and adult venous blood (7.36 [7.35/7.37]). Base deficit (BE) and lactate were significantly higher in neonatal blood (for details see Table 1).

Incubation induced significant changes of $\mathrm{pH}$, base deficit and lactate in both placental and adult blood samples (pH: cord blood: 7.34 at $0 \mathrm{~h}$ to 7.28 [7.24/7.31] at $1 \mathrm{~h}, p<0.05$; adult blood: 7.36 to 7.34 [7.32/7.36], $p<0.05$; for details of base deficit and lactate see Table 1). Lactate concentrations were higher in placental blood during all conditions when compared to adult blood (for details see Table 1). Levels of potassium were higher in cord blood (data not shown) as was the base deficit (Table 1). Anaphylatoxin (C3a and $\mathrm{C} 5 \mathrm{a}$ ) and $\mathrm{sC} 5 \mathrm{~b}-9$ levels increased from baseline incubation with more pronounced acidosis and showed substantial differences between placental blood and adult blood: complement factors were significantly higher in adult blood (Table 2).
Anticoagulation with citrate rather than heparin did not affect levels of lactate nor base deficit (data not shown). The use of citrate decreased baseline levels of pH (cord blood: 7.29 [7.25/7.34] vs 7.34, $p<0.05$; adult blood: 7.32 [7.31/7.34] vs $7.36, p<0.05$ ). Whereas C3a levels were higher in adult samples when treated with heparin (C3a: $1010 \mu \mathrm{g} / 1$ [882/1148; heparin] vs $704 \mu \mathrm{g} / 1$ [292/978; citrate], $p<0.05)$, no significant differences existed in cord blood samples. Levels of C5a were different in cord blood samples (C5a: $0.23 \mu \mathrm{g} / 1 \quad[0.119 / 0.401 ;$ heparin $]$ vs $0.646 \mu \mathrm{g} / 1$ [0.314/1.077; citrate], $p<0.05)$, but did not differ in adult blood specimens (for details see Table 3 ).

\section{Discussion}

In the present investigation we provide evidence of activation of the entire complement cascade by exposure to lactic acid. Baseline complement levels were lower in neonatal as compared to adult blood, activation of complement occurred in a dose-dependent manner and was less pronounced in neonatal blood.

Table 2. $\mathrm{C} 3 \mathrm{a}, \mathrm{C} 5 \mathrm{a}$ and $\mathrm{sC} 5 \mathrm{~b}-9$ in untreated cord and adult blood at $1 \mathrm{~h}$ and after equilibration with lactate $(5.5 \mathrm{mmol} / \mathrm{l}$ and $22 \mathrm{mmol} / \mathrm{l})$

\begin{tabular}{|c|c|c|c|c|c|c|c|}
\hline & \multicolumn{3}{|c|}{ Cord blood } & \multicolumn{3}{|c|}{ Adult blood } & \multirow[t]{2}{*}{ Significance } \\
\hline & median & P25 & P75 & median & P25 & P75 & \\
\hline \multicolumn{8}{|l|}{ С3a $[\mu \mathrm{g} / \mathrm{l}]$} \\
\hline $1 \mathrm{~h}$ & 418 & 182 & 560 & 1010 & 882 & 1148 & $p<0,05$ \\
\hline $5.5 \mathrm{mmol} / \mathrm{l}$ & 498 & 240 & 640 & 1056 & 865 & 1343 & $p<0,05$ \\
\hline $22 \mathrm{mmol} / \mathrm{l}$ & 622 & 243 & 922 & 1381 & 1033 & 1604 & $p<0,05$ \\
\hline \multicolumn{8}{|l|}{$\mathrm{C} 5 \mathrm{a}[\mu \mathrm{g} / \mathrm{I}]$} \\
\hline $1 \mathrm{~h}$ & 0.230 & 0.119 & 0.401 & 0.969 & 0.605 & 1.199 & $p<0,05$ \\
\hline $5.5 \mathrm{mmol} / \mathrm{l}$ & 0.331 & 0.116 & 0.566 & 1.123 & 0.232 & 2.609 & $p<0,05$ \\
\hline $22 \mathrm{mmol} / \mathrm{l}$ & 0.650 & 0.753 & 1.870 & 2.458 & 1.437 & 4.236 & $p<0,05$ \\
\hline \multicolumn{8}{|l|}{$\mathrm{SC} 5 \mathrm{~b}-9[\mu \mathrm{g} / \mathrm{l}]$} \\
\hline $1 \mathrm{~h}$ & 110 & 72 & 173 & 270 & 220 & 358 & $p<0,05$ \\
\hline $5.5 \mathrm{mmol} / \mathrm{l}$ & 289 & 217 & 380 & 437 & 366 & 556 & $p<0,05$ \\
\hline $22 \mathrm{mmol} / \mathrm{l}$ & 406 & 274 & 590 & 589 & 492 & 717 & $p<0,05$ \\
\hline
\end{tabular}




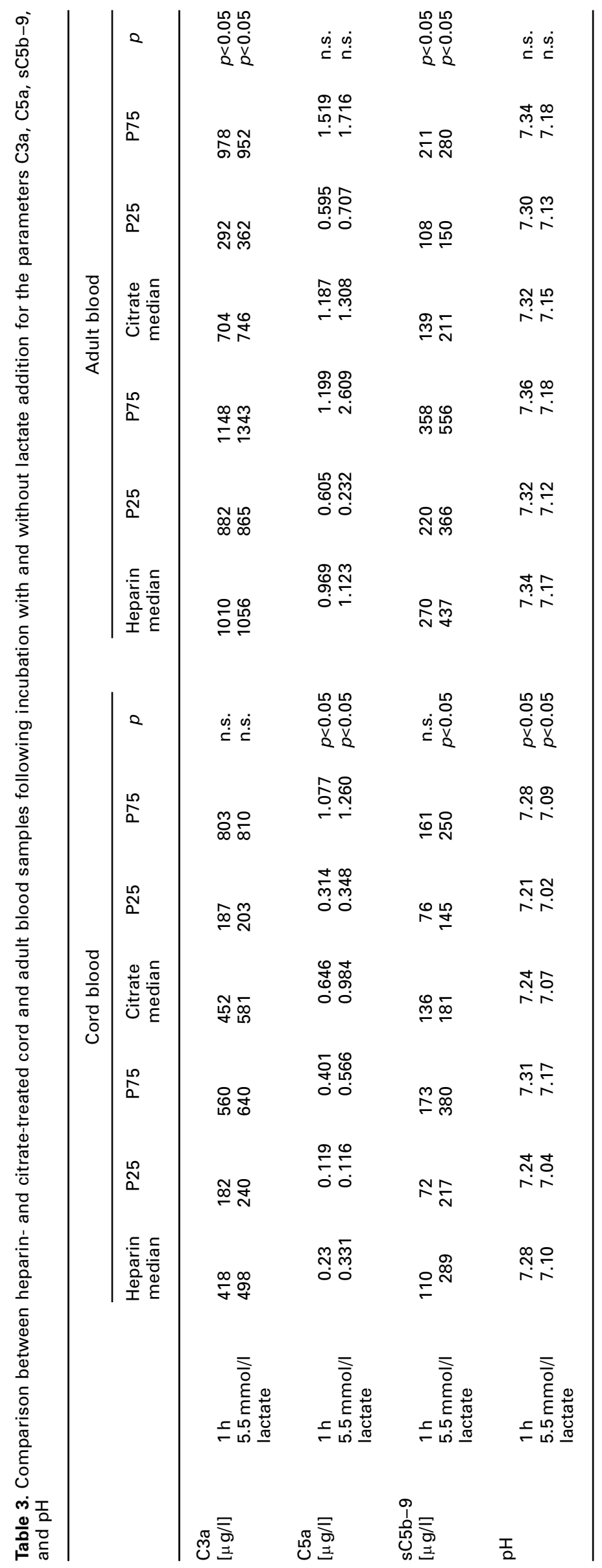


We have previously shown that lactic acidosis activates complement and contact system in blood of healthy adult volunteers. ${ }^{8}$ Furthermore we established reference values for healthy term newborns in umbilical cord blood. ${ }^{9}$ In subsequent investigations we could demonstrate that acidosis itself rather than lactate triggered the activation of the complement components $\mathrm{C} 3$ and $\mathrm{C} 5$ in healthy adult volunteers. ${ }^{7}$ We now provide evidence that complement activation in neonatal blood is less readily achieved and results in lower levels as compared to those in adult blood. Furthermore we show that lactic acidosis initiates the entire cascade of complement factors in neonatal and adult blood.

Lactate, which is the final product of the anaerobic metabolism, reflects the degree of hypoxia in peripheral tissues. Early hyperlactatemia in critically ill children has been shown to be associated with a high mortality. ${ }^{10}$ During septic shock in adults the prediction of multiple organ failure is feasible on the basis of serial blood lactate determinations. ${ }^{11}$ Serial measurements of lactate in ventilated neonates revealed an association between raised lactate levels and mortality. ${ }^{12}$ In addition there is evidence that neonatal base deficit or $\mathrm{pH}$ cannot be used as a proxy measure of serum lactate due to higher levels of base deficit and lower $\mathrm{pH}$ levels in newborn blood. ${ }^{12}$ These results confirm our findings of higher levels of lactate and base deficit and a lower $\mathrm{pH}$ in cord blood as compared to adult blood.

Complement activation has been demonstrated in a variety of neonatal conditions such as early onset infection, ${ }^{13}$ respiratory distress syndrome ${ }^{14}$ and perinatal asphyxia. ${ }^{15}$ Elevation of serum lactate is a common event during the course of these neonatal diseases. The fact that lactic acidosis leads to complement activation in neonatal blood has not been demonstrated previously, comparable data only exist for adult blood. ${ }^{7}$ In addition we have shown that the complement cascade is activated right through to sC $5 b-9$, which indicates that lactic acidosis is capable of initiating an inflammatory response via activation of complement. Coactivation of complement factors and proinflammatory cytokines like IL- 6 has been shown by other investigators during cardiopulmonary bypass. ${ }^{16}$ Similar data exist for IL-1, tumor necrosis factor (TNF- $\alpha$ ), oxygen-derived free radical generation, and complement activation during extracorporeal membrane oxygenation. ${ }^{17}$ Whether these activated mediators or their target cells ultimately lead to cellular damage depends on various factors including the energy status of the cells exposed. A rodent model of CNS trauma demonstrated only recently that inflammatory processes alone are able to initiate a cascade of secondary tissue damage, which resulted in progressive cavitation and glial scarring in the CNS. ${ }^{18}$ Potential mediators of the associated inflammatory activation were fibrinogen, factor $\mathrm{X}$, and complement protein $\mathrm{iC} 3 \mathrm{~b}$. Taken together, there is evidence for a co-activation of several inflammatory mediators by the initial event of lactic acidosis. Activation of this inflammatory cascade may ultimately lead to tissue damage, which may or may not be organ-specific. Clearly further research is required in order to clarify mechanisms of activation and thereby point out potential therapeutic interventions.

Anticoagulation of blood drawn for complement studies is usually performed with heparin due to the interference of EDTA and citrate-related calcium binding with complement assays. ${ }^{19}$ Results of a recent investigation suggest that citrate inhibits complement activation in a dose-dependent manner, which implies that citrate levels below a certain threshold may not interfere with the complement system. ${ }^{20}$ In our investigation anticoagulation with citrate did not influence levels of complement in a uniform and reproducible manner. Until the interference of citrate levels with the quantification of complement levels is further clarified, we cannot recommend the use of citrate for these investigations.

\section{Conclusion}

Lactic acidosis triggers activation of the entire complement cascade in neonatal as well as in adult blood, although less so in neonatal blood. Anaphylatoxin concentrations (C3a, C5a) and levels of the complement activation product $\mathrm{sC} 5 \mathrm{~b}-9$ increase during incubation in a time- and dose-dependent manner with more pronounced lactic acidosis. Anticoagulation with citrate results in unpredictible modulations of complement factors and should be avoided for laboratory evaluation of the complement status.

\section{References}

1. Hill J, Lindsay TF, Ortiz F, Yeh CG, Hechtman HB, Moore FD Jr. Soluble complement receptor type 1 ameliorates the local and remote organ injury after intestinal ischemia-reperfusion in the rat. J Immunol 1992: 149:1723-8

2. Brus F, van Oeveren W, Okken A, Bambang SO. Activation of circulating polymorphonuclear leukocytes in preterm infants with severe idiopathic respiratory distress syndrome. Pediatr Res 1996: 39:456-63.

3. Sonntag J, Wagner MH, Strauss E, Obladen M. Complement and contact activation in term neonates after fetal acidosis. Arch Dis Child Fetal Neonatal Ed 1998: 78:F125-8.

4. Horstick G, Heimann A, Gotze O, et al. Intracoronary application of C1 esterase inhibitor improves cardiac function and reduces myocardial necrosis in an experimental model of ischemia and reperfusion. Circulation 1997: 95:701-8.

5. Turnage RH, Magee JC, Guice KS, Myers SI, Oldham KT. Complement activation by the hydroxyl radical during intestinal reperfusion. Shock 1994: 2:445-50.

6. Rossen RD, Michael LH, Kagiyama A, et al. Mechanism of complement activation after coronary artery occlusion: evidence that myocardial ischemia in dogs causes release of constituents of myocardial subcellular origin that complex with human C1q in vivo. Circ Res 1988: 62:572-84.

7. Emeis M, Sonntag J, Willam C, Strauss E, Walka MM, Obladen M. Acidosis activates complement system in vitro. Mediators Inflamm 1998: 7:417-20.

8. Sonntag J, Emeis M, Strauss E, Obladen M. In vitro activation of complement and contact system by lactic acidosis. Mediators Inflamm 1998: 7:49-51 
9. Sonntag J, Brandenburg U, Polzehl D, Strauss E, Vogel M, Dudenhausen JW, Obladen M. Complement system in healthy term newborns: reference values in umbilical cord blood. Pediatr Dev Pathol 1998: 1:131-5.

10. Hatherill M, McIntyre AG, Wattie M, Murdoch IA. Early hyperlactataemia in critically ill children. Intensive Care Med 2000: 26:314-8.

11. Bakker J, Gris P, Coffernils M, Kahn RJ, Vincent JL. Serial blood lactate levels can predict the development of multiple organ failure following septic shock. Am J Surg 1996: 171:221-6.

12. Deshpande SA, Platt MP. Association between blood lactate and acid-base status and mortality in ventilated babies. Arch Dis Child Fetal Neonatal Ed 1997: 76:F15-20.

13. Zilow EP, Hauck W, Linderkamp O, Zilow G. Alternative pathway activation of the complement system in preterm infants with early onset infection. Pediatr Res 1997: 41:334-9.

14. Enskog A, Bengtsson A, Bengtson JP, Heideman M, Andreasson S, Larsson L. Complement anaphylatoxin $\mathrm{C} 3 \mathrm{a}$ and $\mathrm{C5}$ a formation in premature children with respiratory distress. Eur J Pediatr 1996: 155:41-5.

15. Schrod L, Frauendienst-Egger G, von Stockhausen HB, Kirschfink M. Complement fragment $\mathrm{C} 3 \mathrm{a}$ in plasma of asphyxiated neonates. Eur J Pediatr 1992: 151:688-92.
16. Morgan IS, Ccodispoti M, Sanger K, Mankad PS. Superority of centrifugal pump over roller pump in paediatric cardiac surgery: prospective randomised trial. Eur J Cardiothorac Surg 1998: 13:526-32.

17. Hirthler M, Simoni J, Dickson M. Elevated levels of endotoxin, oxygenderived free radicals, and cytokines during extracorporeal membrane oxygenation. J Pediatr Surg 1992: 27:1199-202.

18. Fitch MT, Doller C, Combs KC, Landreth GE, Silver J. Cellular and molecular mechanisms of glial scarring and progressive cavitation: in vivo and in vitro analysis of inflammation-induced secondary injury after CNS trauma. J Neurosci 2000: 19:8182-98.

19. Zapf S, Loos M. Effect of EDTA and citrate on the functional activity of the first component of complement, $\mathrm{C} 1$, and the $\mathrm{C} 1 \mathrm{q}$ subcomponent. Immunobiology 1985: 170:123-32.

20. Kobayashi E, Kitano E, Kondo H, Kitamura H. Complement activation in citrate plasma-inhibitory effect of anticoagulants on serum complement activation. Rinsho Byori 1999: 47:160-4.

Received 30 November 2000;

accepted 12 December 2000 


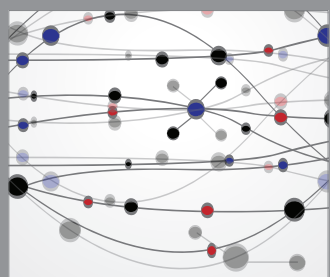

The Scientific World Journal
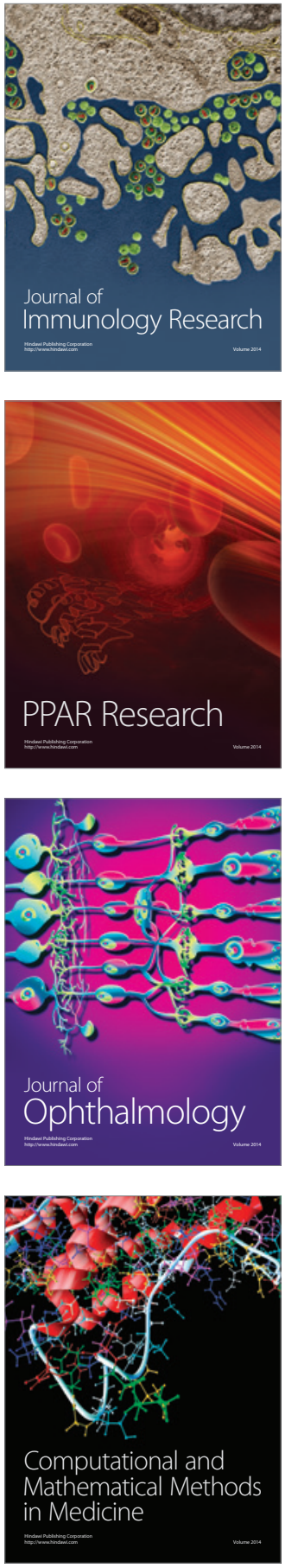

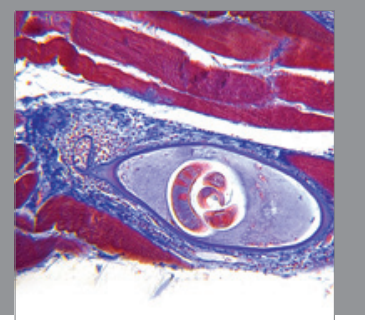

Gastroenterology

Research and Practice
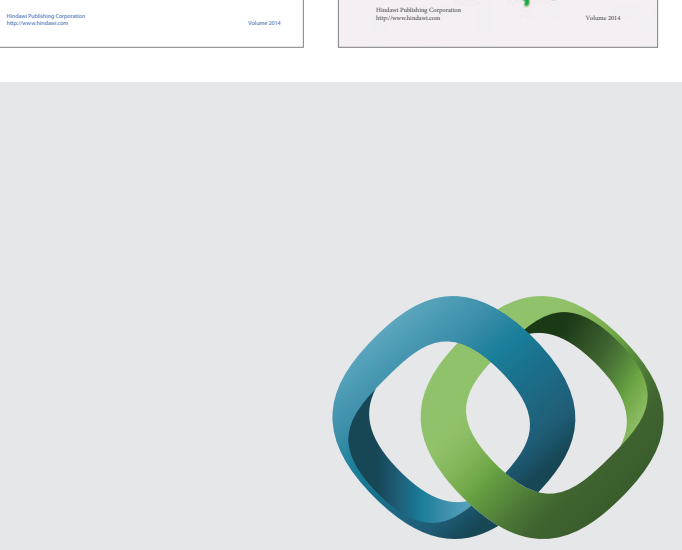

\section{Hindawi}

Submit your manuscripts at

http://www.hindawi.com
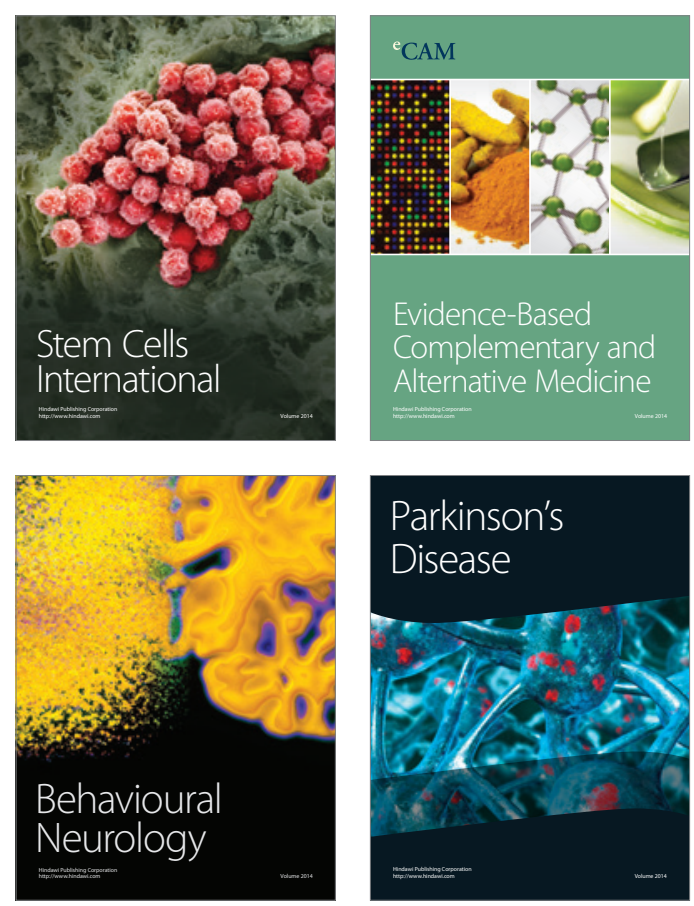

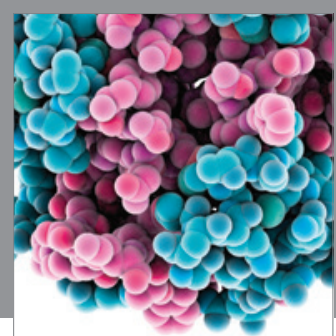

Journal of
Diabetes Research

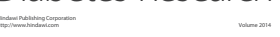

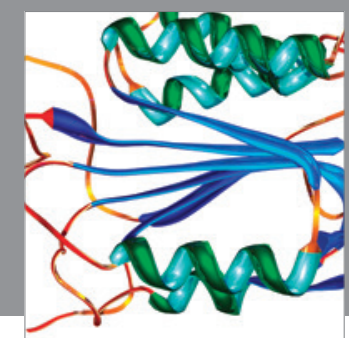

Disease Markers
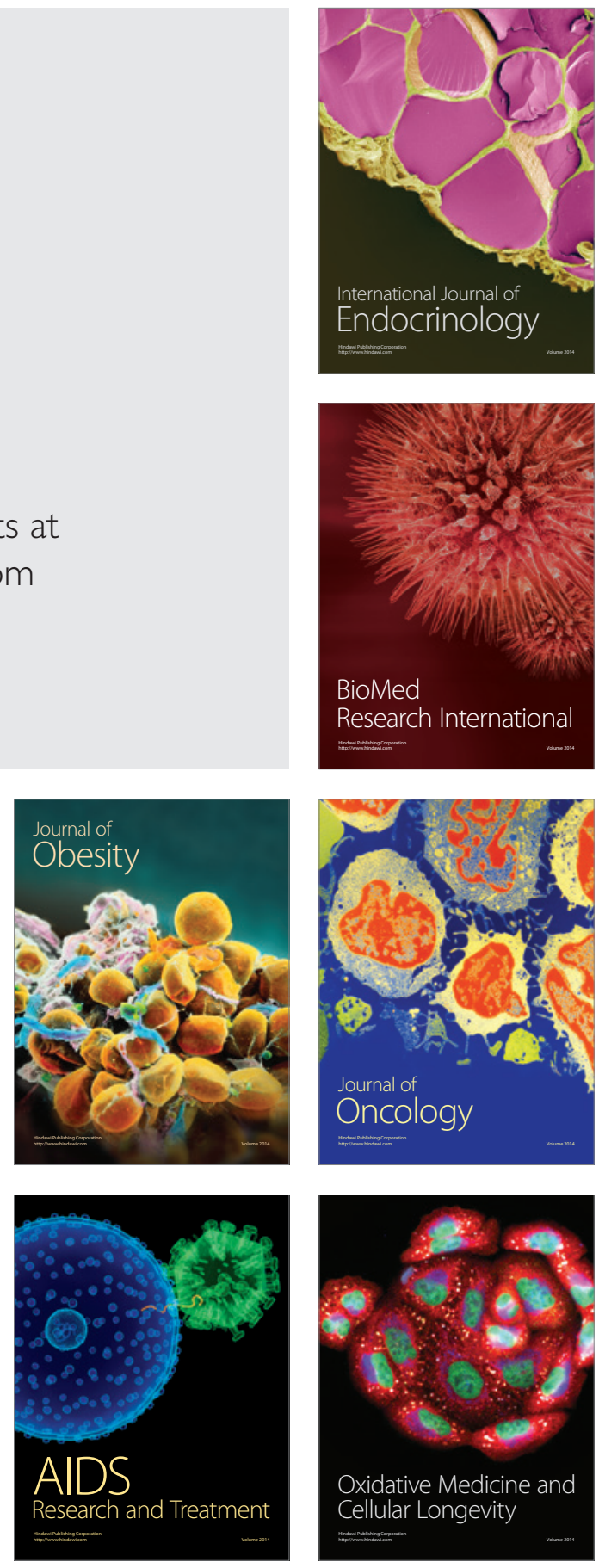